Check for updates

Cite this: RSC Adv., 2019, 9, 30045

\title{
A vanadate-based white light emitting luminescent material for temperature sensing
}

\author{
Nannan Zhang, Jie Li, Jianrong Wang, Ruixia Shi, Ling Chen, (D) Aiyu Zhang (DD* \\ and Ping Yang (D) *
}

Calcium magnesium vanadate-europium vanadate powders with a homogeneous distribution have been prepared by a sol-gel method followed by a sintering process. The as-prepared powders show both broadband emission around $520 \mathrm{~nm}$ and sharp peak emission at $617 \mathrm{~nm}$ under UV light excitation, which are ascribed to the one-electron charge transfer transition in the $\mathrm{VO}_{4}$ tetrahedra and the typical ${ }^{5} \mathrm{D}_{0} \rightarrow$ ${ }^{7} \mathrm{~F}_{2}$ transition of $\mathrm{Eu}^{3+}$. Energy transfer occurs between the vanadate and Eu ions. The emission color of the products can be tuned by controlling the Eu concentration and temperature. White light emission can be obtained at the Eu concentration of $15 \%$ and at room temperature. The temperature related luminescence properties have been studied for the sample with $15 \mathrm{~mol} \%$ Eu. The intensity ratio between the broadband emission (due to $\mathrm{VO}_{4}$ tetrahedra) and the sharp peak emission (due to $\mathrm{Eu}^{3+}$ ions) decreases as the temperature increases in a linear relationship. The relative sensitivity $\left(S_{R}\right)$ of this luminescent temperature sensor has been calculated and a maximum has been gained at $455 \mathrm{~K}$ with the value equal to $1.83 \% \mathrm{~K}^{-1}$

Received 9th August 2019

Accepted 12th September 2019

DOI: 10.1039/c9ra06193b

rsc.li/rsc-advances

thermally coupled levels (TCLs) of lanthanide ions $\left(\mathrm{Ln}^{3+}\right),{ }^{28-36}$

\section{Introduction}

In recent years, photoluminescent materials have attracted great interest as irreplaceable lighting devices in the area of field emission displays (FEDs), plasma display panels (PDPs), X-ray detectors, and white-light emitting diodes (w-LEDs), due to their excellent luminous efficiency and energy saving properties..$^{1-5}$

Among a lot of luminescent materials, rare-earth ion doped phosphors have been extensively studied and considered as potential light source materials. ${ }^{6,7}$ Many compounds have been applied as the matrix materials for rare-earth ions, including zinc oxides, fluorides, aluminates, silicates, zirconates, vanadates, molybdates, and phosphates. ${ }^{8-17}$ As an excellent red phosphor, $\mathrm{Eu}^{3+}$ doped $\mathrm{YVO}_{4}$ (ref. 18 and 19) has attracted much attention from researchers, and the energy transfer from the $\mathrm{VO}_{4}{ }^{3-}$ groups to the $\mathrm{f}-\mathrm{f}$ state of $\mathrm{Eu}^{3+}$ ions is observed. In fact, vanadates of certain metals ( $\mathrm{Zn}, \mathrm{Mg}, \mathrm{Sr}, \mathrm{Cs}, \mathrm{K}$ and so on) show intrinsic luminescence due to the one-electron charge transfer transition in the $\mathrm{VO}_{4}$ tetrahedra. ${ }^{20-22}$

The high-precision temperature sensing plays a key role in controlling reaction process, product performance, and safety in production. ${ }^{23-25}$ Physical probes such as thermometers and thermocouples, unfortunately, have limited utilities in the situation of noncontact, small volumes, as well as high spatial resolutions. ${ }^{26,27}$ Meanwhile, optical temperature sensors, which exploit the temperature-dependent fluorescence intensities of

School of Material Science and Engineering, University of Jinan, 250022, Jinan, China. E-mail:mse_zhangay@ujn.edu.cn; mse_yangp@ujn.edu.cn such as $\mathrm{Ho}^{3+}, \mathrm{Pr}^{3+}, \mathrm{Er}^{3+}, \mathrm{Gd}^{3+}$, serves as a feasible method benefiting from the rapid-response fluorescence spectroscopy techniques. For example, Yang et al. proposed a strategy using optical temperature sensing behavior of $\mathrm{Er}^{3+}-\mathrm{Yb}^{3+}$ co-doped $\mathrm{NaY}\left(\mathrm{MoO}_{4}\right)_{2}$ phosphor, and a maximum relative sensitivity value of $0.00969 \mathrm{~K}^{-1}$ are observed at $439 \mathrm{~K}$.

In the present work, $\mathrm{Eu}^{3+}$ ions were introduced into a vanadate matrix $\mathrm{Ca}_{5} \mathrm{Mg}_{4} \mathrm{~V}_{6} \mathrm{O}_{24}$ (called CMV hereafter), which show yellow-green colored luminescence emission of $\mathrm{VO}_{4}{ }^{3-}$ under UV light excitation. Our study focused on the luminescent property and luminescent response on different temperature ranging from $300 \mathrm{~K}$ to $480 \mathrm{~K}$.

\section{Experimental section}

\subsection{Preparation of $\mathrm{Ca}_{5} \mathrm{Mg}_{4} \mathrm{~V}_{6} \mathrm{O}_{24}: \mathrm{Eu}^{3+}$ phosphors}

Powders of $\mathrm{Ca}_{5} \mathrm{Mg}_{4} \mathrm{~V}_{6} \mathrm{O}_{24}$ (CMV) with $\mathrm{Eu}^{3+}$ addition were prepared by a sol-gel method followed by a sintering process. $0.083 \mathrm{~g} \mathrm{CaCO}_{3}$ (99.99\%), $0.0647 \mathrm{~g} \quad 4 \mathrm{MgCO}_{3} \cdot \mathrm{Mg}(\mathrm{OH})_{2} \cdot 5 \mathrm{H}_{2} \mathrm{O}$ (99.99\%), $0.117 \mathrm{~g} \mathrm{NH} \mathrm{VO}_{3}$ (99.9\%, A.R.) and $1.051 \mathrm{~g}$ citric acid were mixed in a solution of $\mathrm{HNO}_{3}$ (A.R.). The doped concentration of rare earth ion $\left(\mathrm{Eu}^{3+}\right)$ was from $0.5 \mathrm{~mol} \%$ to $20 \mathrm{~mol} \%$ $\left(7.5 \times 10^{-3}\right.$ to $\left.0.3 \mathrm{mmol}\right)$ compared with the total mole amount of $\mathrm{Ca}^{2+}$ and $\mathrm{Mg}^{2+}$ in $\mathrm{Ca}_{5} \mathrm{Mg}_{4} \mathrm{~V}_{6} \mathrm{O}_{24}$ host. The practical ratio of metal ions to citric acid that served as a chelating agent for metal ions was 1 to 2 . The mixed solution was stirred under heating, dried in an oven, and finally sintered at $400{ }^{\circ} \mathrm{C}$ for $3 \mathrm{~h}$, then heated up to $800{ }^{\circ} \mathrm{C}$ for $5 \mathrm{~h}$. The obtained white powder 
(called CMV: $\mathrm{Eu}^{3+}$ ) was cooled down and ground for further investigation.

\subsection{Preparation of luminescent device}

Transparent sheets of the phosphor were prepared with Sylgard 184. Sylgard 184 (Dow Corning) is of the polydimethylsiloxane (PDMS) family and is an optically clear and inert material. About $1 \mathrm{~g}$ resin and $0.1 \mathrm{~g}$ curing agent was mixed with $0.1 \mathrm{~g}$ powder sample and allowed to stand at room temperature for at least $24 \mathrm{~h}$. The sheet was obtained by a self-leveling method. The luminescent sheets were coated on a four-beads $310 \mathrm{~nm}$ LED as shown in Fig. 1. Subsequent emission observation has all been conducted to these simple devices.

\subsection{Characterization}

The X-ray diffraction (XRD) patterns for all target samples were registered using the Bruker $\mathrm{D} 8$ Advance with $\mathrm{Cu} \mathrm{K} \alpha_{1,2}$ radiation and $2 \theta$ range from $10^{\circ}$ to $90^{\circ}$, and analyzed by using Jade-5.0 software program. The scanning electron microscope (SEM) patterns and Energy dispersive spectrometer (EDS) were obtained by using a Quanta FEG 250 Field Emission Scanning Electron Microscope. The photoluminescence (PL) and excitation (PLE) spectrum under different temperatures (above the room temperature) of the samples were evaluated with a fluorescence spectrophotometer (F-4600, Hitachi, Japan) equipped with a xenon lamp as the excitation light source. The samples sealed in a metallic box were heated to and kept at a special temperature. The measure button was pressed immediately after the sample at the special temperature being transferred from the heater into the fluorescence spectrophotometer. The temperature-related PL spectra under $0{ }^{\circ} \mathrm{C}$ were measured using a FLS920 fluorescence spectrometer with a liquid nitrogen cryostat.

\section{Results and discussion}

\subsection{Morphology and phase distribution}

In order to learn about the phase purity and crystallization of $\mathrm{CMV}: x \mathrm{Eu}^{3+}$ powders, the patterns of XRD were measured and

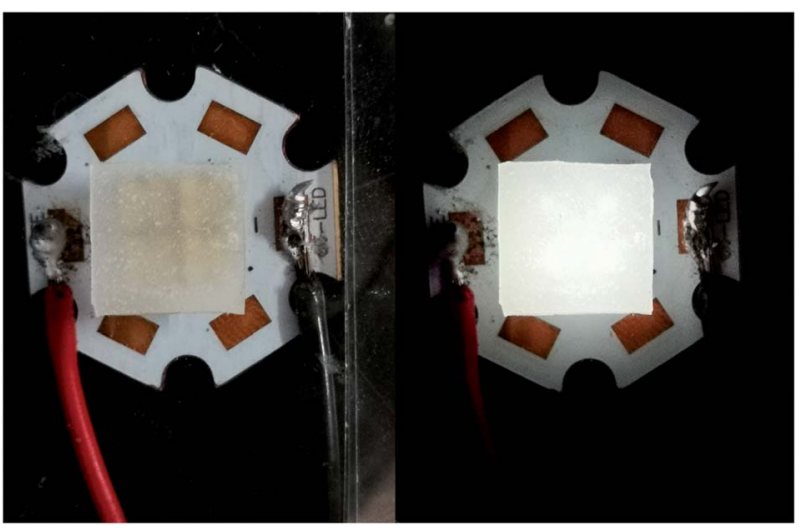

Fig. 1 Luminescent sheets on a four-beads $310 \mathrm{~nm}$ LED with the status of off (left) and on (right). shown in Fig. 2. The pattern of CMV: $x \mathrm{Eu}^{3+}(x=0)$ matches well with $2002588\left(\mathrm{Ca}_{5} \mathrm{Mg}_{4} \mathrm{~V}_{6} \mathrm{O}_{24}\right)$ which is selected in the Crystallography Open Database (COD). With the increase of $x$, a new phase $\mathrm{EuVO}_{4}$ emerges. The content of $\mathrm{EuVO}_{4}$ phase rises dramatically with the $\mathrm{Eu}^{3+}$ concentration, it should be noted that the phase of $\mathrm{EuVO}_{4}$ exists even at a concentration as low as $0.5 \mathrm{~mol} \%$, which indicates that $\mathrm{EuVO}_{4}$ is easy to be formed independently rather than enter into the crystal lattice of matrix material. The products are still named as CMV: $x \mathrm{Eu}^{3+}$ powders, although in fact they are composed of $\mathrm{Ca}_{5} \mathrm{Mg}_{4} \mathrm{~V}_{6} \mathrm{O}_{24}$ and $\mathrm{EuVO}_{4}$ phases.

A schematic of the crystal structure of $\mathrm{Ca}_{5} \mathrm{Mg}_{4}\left(\mathrm{VO}_{4}\right)_{6}$ is presented in Fig. 3(a). In this vanadate garnet structure, $\mathrm{Ca}^{2+}$ ions are located in eightfold dodecahedral sites (i.e. a distorted cube with $\mathrm{D}_{2}$ symmetry). The $\mathrm{Mg}^{2+}$ ions are in six fold octahedral sites. The metal ion $\mathrm{V}^{5+}$ (in isolated $\left[\mathrm{VO}_{4}\right]^{3-}$ ) completely occupies the fourfold $T_{\mathrm{d}}$ site. ${ }^{37,38}$ The crystal structure of $\mathrm{Ca}_{5^{-}}$ $\mathrm{Mg}_{4}\left(\mathrm{VO}_{4}\right)_{6}$ shows a distortion after leading $1 \% \mathrm{Eu}^{3+}$ into the position of $\mathrm{Ca}^{2+}$ as shown in Fig. 3(b). The detailed data are summarized in Table 1. It is obvious that with the concentration of $\mathrm{Eu}^{3+}$ increasing, the lattice constant and unit cell expand modestly, and once the value of $x$ exceeding $10 \%$, the lattice begin to shrink slightly, indicating that the saturation of $\mathrm{Eu}^{3+}$ in the $\mathrm{Ca}_{5} \mathrm{Mg}_{4}\left(\mathrm{VO}_{4}\right)_{6}$ crystalline lattice.

SEM and EDS images of CMV: $x \mathrm{Eu}^{3+}(x=0,15 \mathrm{~mol} \%)$ are presented in Fig. 4. The grain size of sample with $x=0$ is larger than that of the one with $x=15 \mathrm{~mol} \%$. Comparing with pure $\mathrm{CMV}$, the grains of CMV:15 mol\% $\mathrm{Eu}^{3+}$ show tighter arrangement and have more unclear particle edge. According to EDS analysis, the homogeneous distribution of each elements can be found, which illustrates that the two phases CMV and $\mathrm{EuVO}_{4}$ are combined together in the micro scale, distinguished from samples mixed mechanically.

\subsection{Luminescence properties of $\mathrm{CMV}: x \mathrm{Eu}^{3+}$ samples}

Fig. 5 exhibits PL emission and excitation spectra of typical $\mathrm{CMV}: x \mathrm{Eu}^{3+}$ samples. One can notice from Fig. 5(a) that the emission spectra of CMV: $x \mathrm{Eu}^{3+}(x=1.5-20 \mathrm{~mol} \%)$ consists of

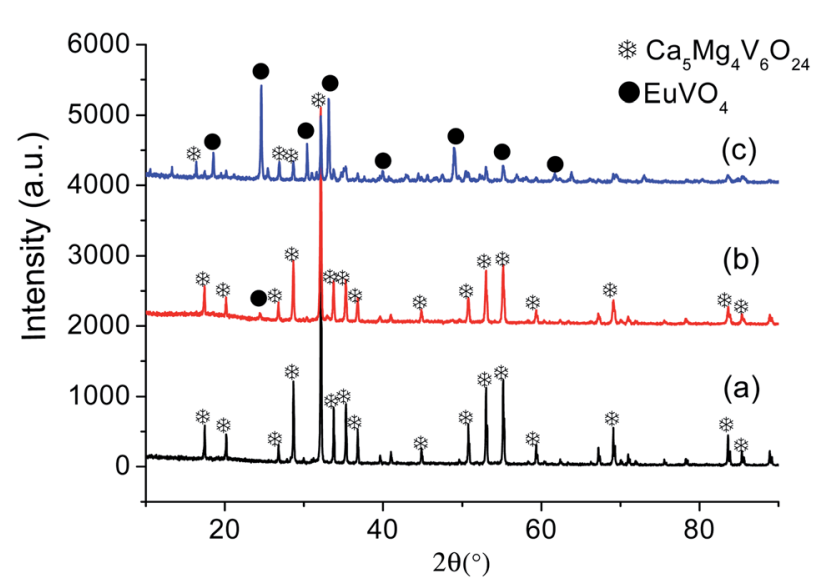

Fig. 2 XRD patterns of CMV: $x \mathrm{Eu}^{3+}$ with $x=$ (a) 0 , (b) $0.5 \mathrm{~mol} \%$, (c) $15 \mathrm{~mol} \%$. 
(a)

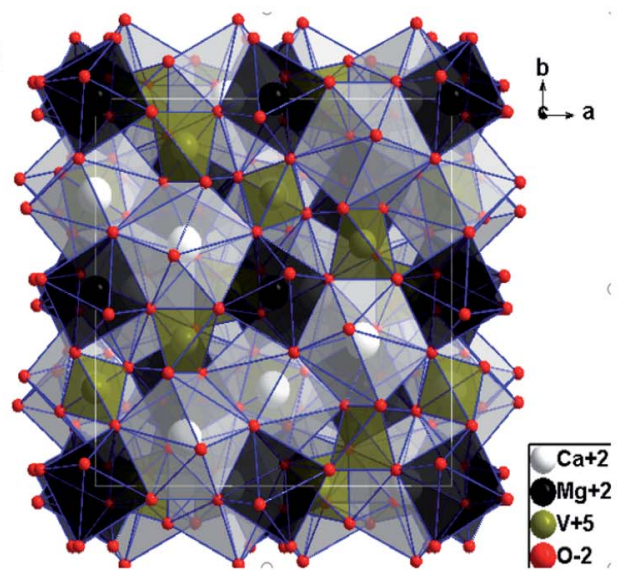

(b)

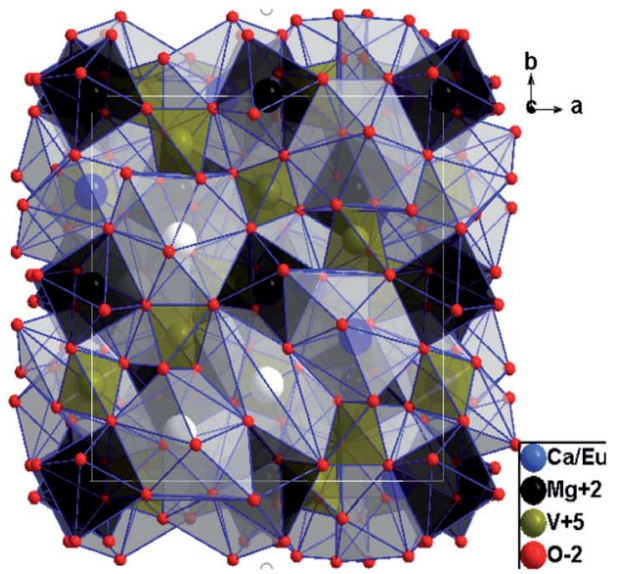

Fig. 3 Schematic view of crystal structure along c-direction for (a) $\mathrm{Ca}_{5} \mathrm{Mg}_{4}\left(\mathrm{VO}_{4}\right)_{6}$ and (b) $\mathrm{Ca}_{5} \mathrm{Mg}_{4}\left(\mathrm{VO}_{4}\right)_{6}$ with Eu ${ }^{3+}$ replacing $1 \% \mathrm{Ca}^{2+}$.

typical broadband emission and sharp peak emission while the spectrum of pure CMV only has broadband emission. The broadband emission of vanadate phosphors ranging from $400 \mathrm{~nm}$ to $800 \mathrm{~nm}$ with the maximum at $520 \mathrm{~nm}$ corresponds to charge transition $(\mathrm{CT})^{7,16,17}$ of $\left[\mathrm{VO}_{4}\right]^{3-}$. The sharp peak detected at $617 \mathrm{~nm}$ corresponds to electric dipole transition $\left({ }^{5} \mathrm{D}_{0} \rightarrow{ }^{7} \mathrm{~F}_{2}\right)$ of $\mathrm{Eu}^{3+}$, which indicates that $\mathrm{Eu}^{3+}$ ions occupy non-inversion symmetry sites in the crystal lattice. The spectra in Fig. 5(a) were normalized according to the PL intensity at $520 \mathrm{~nm}$. It can be found that the relative intensity of the sharp emission peak of $\mathrm{Eu}^{3+}$ at $617 \mathrm{~nm}$ increases with the $x$ value and reaches a maximum point at $x=15 \%$. The relative low intensity for the sample with $20 \% \mathrm{Eu}^{3+}$ may be attributed to concentrationquenching effect. ${ }^{39-42}$

The excitation spectra of different $\mathrm{Eu}^{3+}$ concentration were measured at two emission wavelength, $520 \mathrm{~nm}$ and $617 \mathrm{~nm}$, which were shown in Fig. 5(b) and (c) respectively. The excitation spectra monitored at $520 \mathrm{~nm}$ are typical excitation peaks of $\left[\mathrm{VO}_{4}\right]^{3-}$, which show a light red-shift with $\mathrm{Eu}^{3+}$ concentration increasing as shown in Fig. 5(b). The excitation peak of $\left[\mathrm{VO}_{4}\right]^{3-}$ is asymmetric and can be decomposed into two Gaussian components $\mathrm{E} x_{1}\left({ }^{1} \mathrm{~A}_{1} \rightarrow{ }^{1} \mathrm{~T}_{1}, 276 \mathrm{~nm}\right)$ and $\mathrm{E} x_{2}\left({ }^{1} \mathrm{~A}_{1} \rightarrow{ }^{1} \mathrm{~T}_{2}, 314\right.$ $\mathrm{nm})$ corresponding to the intrinsic transitions in $\mathrm{VO}_{4}$ tetrahedron $^{43,44}$ as shown in the diagram of Fig. 6. The red-shift observed in Fig. 5(b) is actually the change of relative intensity between $\mathrm{E} x_{2}$ and $\mathrm{E} x_{1}$, which reflects the structure modification of CMV induced by small amount of $\mathrm{Eu}^{3+}$ addition.

Table 1 Lattice constant and unit cell volume of CMV structure with different concentrations of $\mathrm{Eu}^{3+}$ (addition in the preparation process)

\begin{tabular}{llllll}
\hline$x$ & $a$ & $b$ & $c$ & $\alpha, \beta, \gamma\left({ }^{\circ}\right)$ & Vol \\
\hline 0 & 12.4630 & 12.4360 & 12.4360 & 90 & 1923.3 \\
$1.5 \%$ & 12.4397 & 12.4397 & 12.4397 & 90 & 1925.0 \\
$2.0 \%$ & 12.4399 & 12.4399 & 12.4399 & 90 & 1925.1 \\
$2.5 \%$ & 12.4453 & 12.4453 & 12.4453 & 90 & 1927.6 \\
$10 \%$ & 12.4524 & 12.4524 & 12.4524 & 90 & 1930.9 \\
$15 \%$ & 12.4461 & 12.4461 & 12.4461 & 90 & 1928.0 \\
$20 \%$ & 12.4430 & 12.4430 & 12.4430 & 90 & 1926.5
\end{tabular}

The excitation spectra obtained at $617 \mathrm{~nm}$ (Fig. 5(c)) comprise both broad band between $220 \mathrm{~nm}$ and $350 \mathrm{~nm}$ and typical sharp excitation peaks of $\mathrm{Eu}^{3+}$. Both $\mathrm{Eu}-\mathrm{O}$ charge

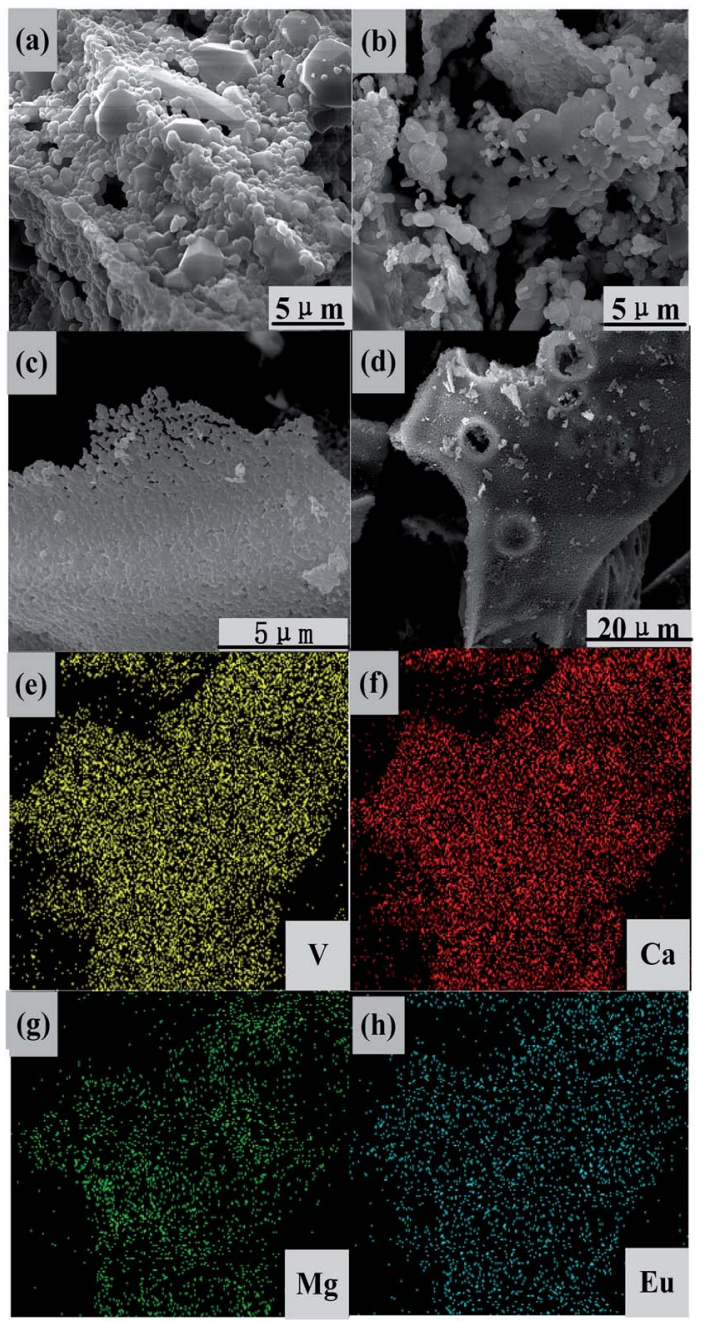

Fig. 4 SEM images of CMV:xEu ${ }^{3+}$, (a) and (b) with $x=0$ and (c) and (d) $x$ $=15$, and $(\mathrm{e})-(\mathrm{h})$ EDS patterns based on (d). 
transfer band (CTB $)^{45-47}$ and $\mathrm{V}-\mathrm{O}$ charge transfer are in the wavelength range from $220 \mathrm{~nm}$ to $350 \mathrm{~nm}$. The broad bands in Fig. 5(c) show a blue-shift with $x$ value which is resulted from the enhancement of the component peak around $270 \mathrm{~nm}$. The excitation around $270 \mathrm{~m}$ can be both ascribed to Eu-O CTB and $\mathrm{E} x_{1}$ of $\left[\mathrm{VO}_{4}\right]^{3-}$ excitation. Based on the above discussion, we deduced that the energy of $\mathrm{Eu}^{3+}$ emission at $617 \mathrm{~nm}$ mainly come from the energy transfer between $\left[\mathrm{VO}_{4}\right]^{3-}$ and $\mathrm{Eu}^{3+}$ at low $\mathrm{Eu}^{3+}$ concentration, and with the raise of $\mathrm{Eu}^{3+}$ concentration both energy transfer from $\left[\mathrm{VO}_{4}\right]^{3-}$ to $\mathrm{Eu}^{3+}$ and $\mathrm{Eu}-\mathrm{O}$ CTB contribute to $\mathrm{Eu}^{3+}$ emission at $617 \mathrm{~nm}$.

No evidence of $\mathrm{Eu}^{2+}$ was found in all excitation and emission spectra. In addition, all the samples were prepared in air. No reductive gas was used in the preparation process. Thus, it is convinced that all the europium element exists in the form of trivalent $\mathrm{Eu}^{3+}$ ions.

According to the above discussion, the emission process was illustrated by diagram in Fig. 6. After absorbing a UV photon, the electron of the tetrahedral $\left[\mathrm{VO}_{4}\right]^{3-}$ group is excited from ${ }^{1} \mathrm{~A}_{1}$ state to ${ }^{3} \mathrm{~T}_{1,2}$ state. The energy of the excited electrons is partially transferred to $\mathrm{Eu}^{3+}$ ions, and emitted red light by the wellknown ${ }^{5} \mathrm{D}_{0} \rightarrow{ }^{7} \mathrm{~F}_{\mathrm{J}}$ transitions of $\mathrm{Eu}^{3+}$ ions. The residual energy emitted yellow-green light by ${ }^{3} \mathrm{~T}_{1,2} \rightarrow{ }^{1} \mathrm{~A}_{1}$ transition of $\left[\mathrm{VO}_{4}\right]^{3-}$ tetrahedra.

It has been found from Fig. 5(a) that the relative intensity of $617 \mathrm{~nm}$ emission comparing with that of the $520 \mathrm{~nm}$
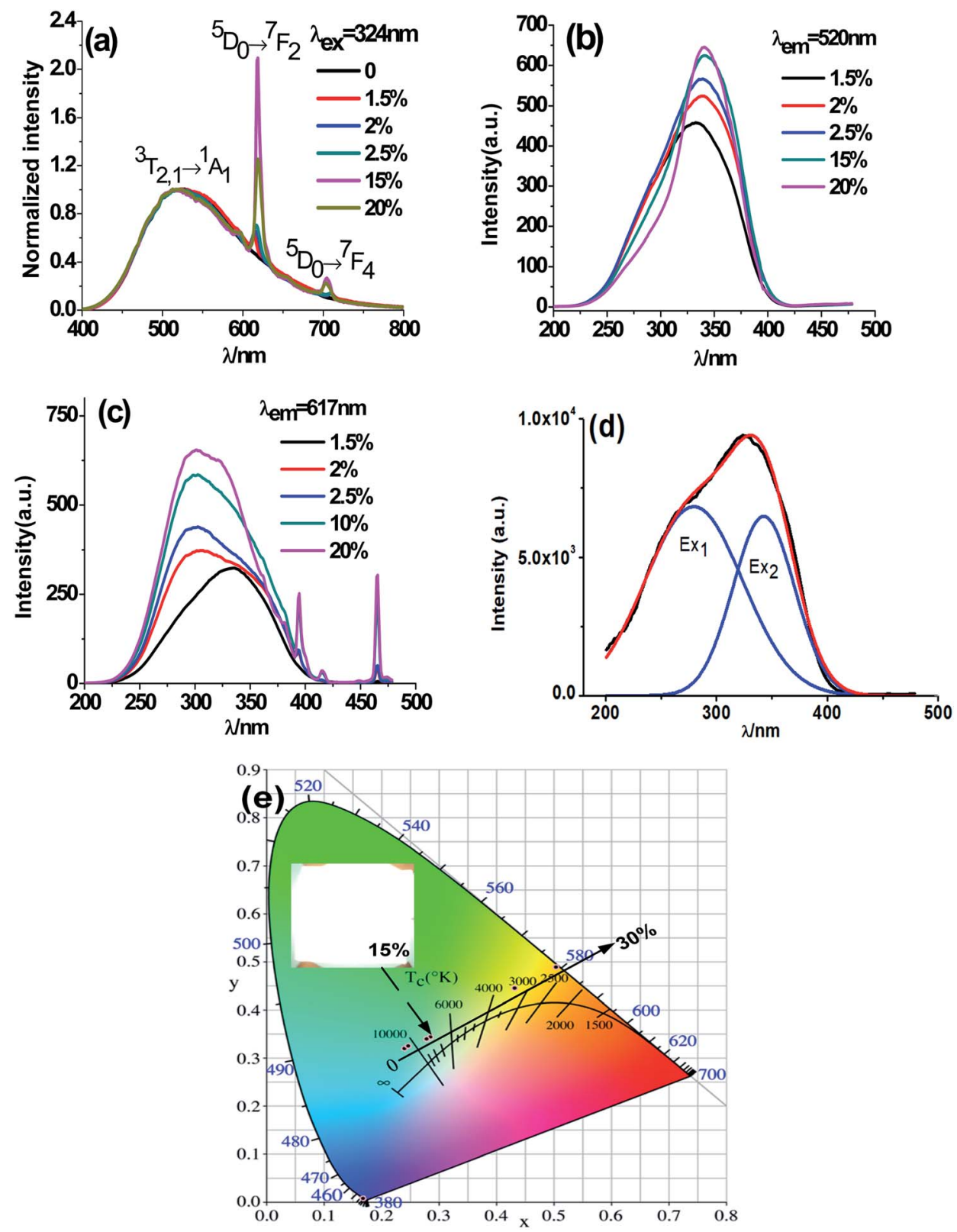

Fig. 5 (a) PL emission (normalized according to the PL intensity at $520 \mathrm{~nm}$ ) and (b and c) excitation spectra of $\mathrm{CMV}: x \mathrm{~mol} \% \mathrm{Eu}{ }^{3+}$ with different $x$ value; (d) Gaussian peaks defined as $\mathrm{Ex}_{1}$ and $\mathrm{Ex} x_{2}$; (e) CIE coordinates of samples with different Eu ${ }^{3+}$ concentration $x(x=0,10 \%, 15 \%, 20 \%, 30 \%$; the inset of (e), the photograph of sheet containing CMV:15 mol\% Eu ${ }^{3+}$ under $310 \mathrm{~nm}$ light excitation. 


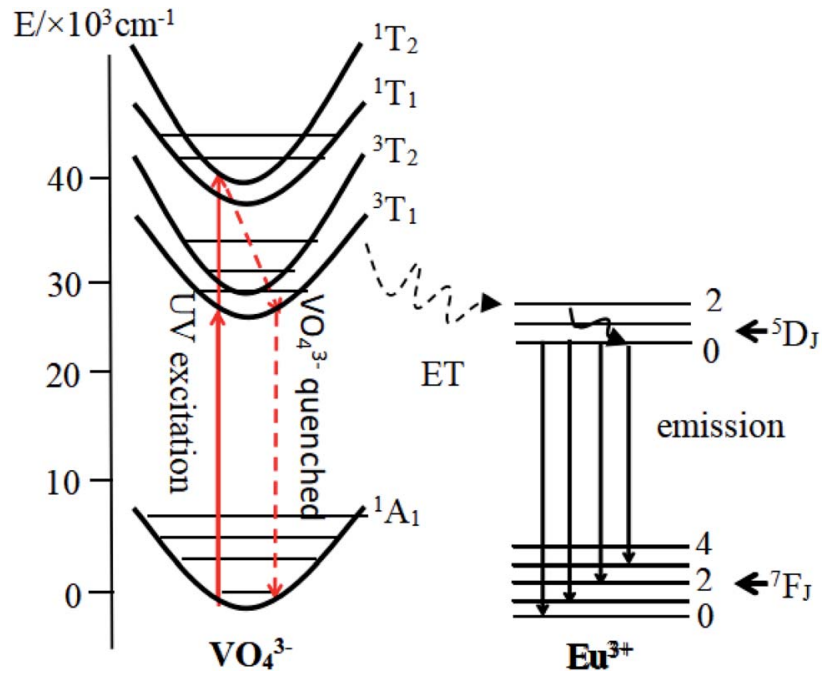

Fig. 6 The schematic diagram of energy level transition.

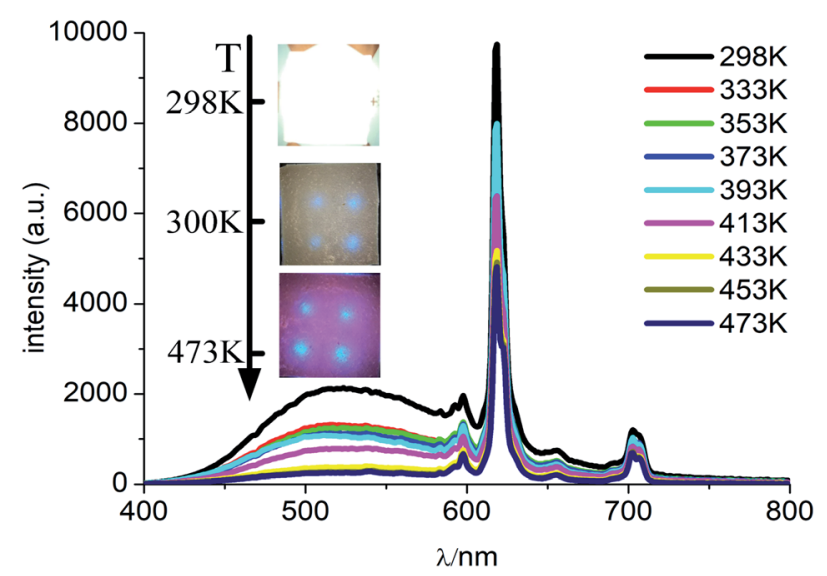

Fig. $7 \mathrm{PL}$ spectra of $\mathrm{CMV}: 15 \mathrm{~mol} \% \mathrm{Eu}^{3+}$ at different temperatures excited by $310 \mathrm{~nm}$ light. Inset is the photographs of the device with the UV light on at different temperature.

emission varies with $\mathrm{Eu}^{3+}$ concentration, so that luminous color is dependent on $\mathrm{Eu}^{3+}$ addition. In fact, the emission color of the obtained phosphor can be tuned easily from yellow-green to white, and eventually to red by manipulating the addition amount of $\mathrm{Eu}^{3+}$ and the white light emission is gained when $x=15 \%$, which is shown in Fig. 5(e).

\subsection{Temperature-dependent luminescent properties of CMV:15 mol\% $\mathrm{Eu}^{3+}$}

In order to examine the trend of temperature-dependent luminescent properties, we carried out a study on the PL emission spectra of $\mathrm{CMV}: 15 \mathrm{~mol} \% \mathrm{Eu}^{3+}$ powder sample at different temperature (from 300 to $480 \mathrm{~K}$ ), which were recorded in Fig. 7.

As shown in Fig. 7, the intensities of broadband emission (at $520 \mathrm{~nm}$ ) and sharp peak emission (at $617 \mathrm{~nm}$ ) decrease with temperature rising, and the reducing speed at $520 \mathrm{~nm}$ is quicker comparing with that of $617 \mathrm{~nm}$. The difference in speed could be observed in Fig. 8(a), and the ratio (defined as $R$ ) of $I_{520}$ to $I_{617}$ changes linearly. The luminous color is studied continuously by heating the material from $300 \mathrm{~K}$ to $480 \mathrm{~K}$. Color changes can be observed visibly in the inset of Fig. 7, presenting that luminous color could be tuned from white to red via yellow. The CIE coordinates at different temperature are on a line passing by the CIE coordinate image as shown in Fig. 9. The white phosphor has a correlated color temperature of $4964 \mathrm{~K}$ and CIE coordinates of (0.3496, 0.3935).

Because of the temperature-dependent luminescent property, the materials may be applied as temperature sensing materials. The relative sensitivity $S_{\mathrm{R}}$ defined as the relative change of $R$ with respect to the variation of $T$ is obtained as follows ${ }^{20,48-50}$

$$
S_{\mathrm{R}}=R \times \frac{\mathrm{d} \frac{1}{R}}{\mathrm{~d} T}
$$

where $R$ is the ratio of $I_{520}$ and $I_{617}$ corresponding to different temperatures (Fig. 8(a)). $T$ is absolute temperature. $S_{\mathrm{R}}$ value at different temperature was calculated using eqn (1) and listed in Fig. 8(b). Fitting of these data is shown as solid lines in Fig. 8(b). The calculated maximum value of $S_{\mathrm{R}}$ equals to $1.83 \% \mathrm{~K}^{-1}$ at $455 \mathrm{~K}$ with an excitation wavelength of $310 \mathrm{~nm}$, which is a relatively high sensitivity compared
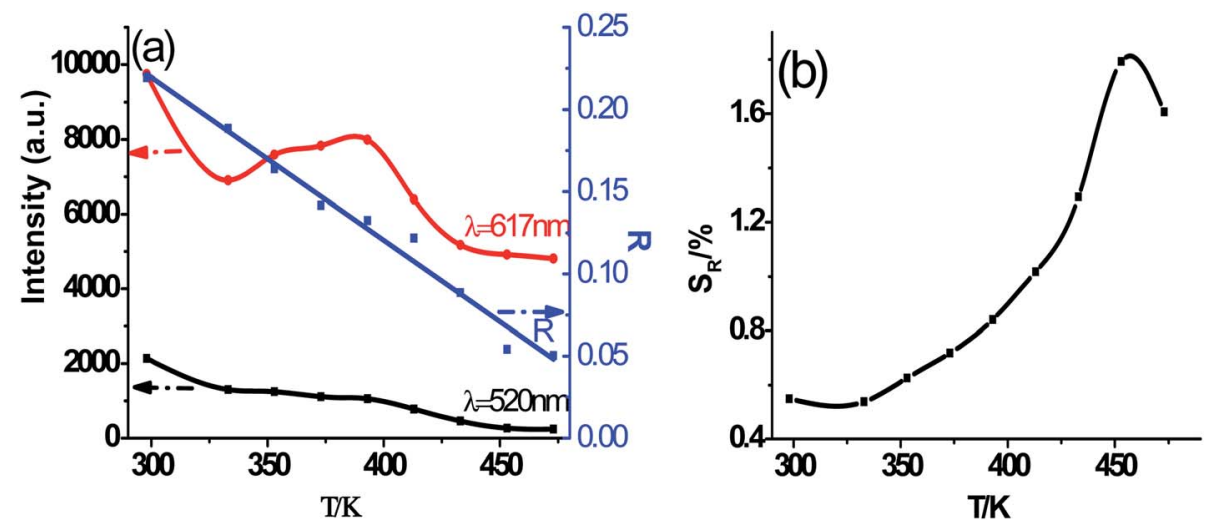

Fig. 8 (a) Luminescence intensity variation with temperature elevating at $520 \mathrm{~nm}$ and $617 \mathrm{~nm}$, and ratio $(R)$ of $/ 520$ to $/ 617$, (b) the relative sensitivity $\left(S_{R}\right)$. 


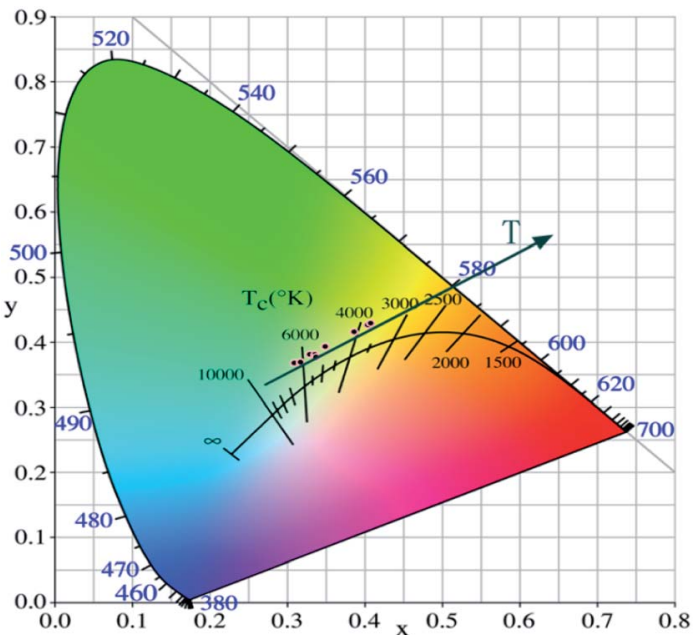

Fig. $9 \mathrm{CIE}$ coordinates under different temperatures (from $300 \mathrm{~K}$ to $480 \mathrm{~K})$.

with previously reported optical temperature sensors such as $\beta-\mathrm{NaYF}_{4}: \mathrm{Nd}^{3+}$ and $\beta-\mathrm{NaYF}_{4}: \mathrm{Yb}^{3+} / \mathrm{Er}^{3+}$. The intrinsic yellow-green luminescence of vanadates has been reported in the previous work ${ }^{20-22}$. A white-light emission can be realized in this work by introducing a common $\mathrm{Eu}^{3+}$ into a very low-cost $\mathrm{Ca}_{5} \mathrm{Mg}_{4}\left(\mathrm{VO}_{4}\right)_{6}$ host. The obtained material shows a luminescence temperature sensing property with a high $S_{\mathrm{R}}$. Comparing with the luminescence temperature sensor such as $\mathrm{GdVO}_{4}: \mathrm{Sm}^{3+}$ and $\mathrm{Y}_{2} \mathrm{O}_{3}: \mathrm{Eu}^{3+}$ in the previous literature ${ }^{51,52}$, the prepared material reaches a similar $S_{\mathrm{R}}$ in the absence of rare earth element in the host, which will result in a significant cost reduction. Interestingly, the temperature-dependent effect is limited below $293 \mathrm{~K}$. The intensity ratio $(R)$ keeps almost a constant value when the temperature is controlled under $0{ }^{\circ} \mathrm{C}$, which is shown in Fig. 10. The mechanism of this phenomenon remains to be further studied.

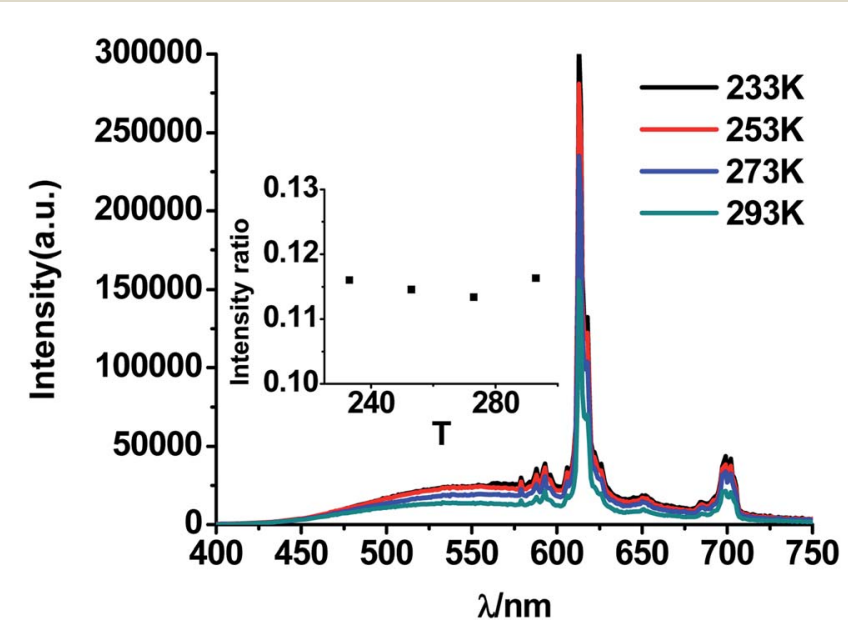

Fig. $10 \mathrm{PL}$ spectra of $\mathrm{CMV}: 15 \mathrm{~mol} \% \mathrm{Eu}^{3+}$ at different temperatures (under $0^{\circ} \mathrm{C}$ ) excited by $310 \mathrm{~nm}$ light. Inset is the ratio of $I_{520}$ to $I_{617}$ at different temperature (under $0^{\circ} \mathrm{C}$ ).

\section{Conclusion}

Eu-contained calcium magnesium vanadate $\left(\mathrm{CMV}: \mathrm{Eu}^{3+}\right)$ phosphors were prepared and the product is a mixture of $\mathrm{Ca}_{5} \mathrm{Mg}_{4}{ }^{-}$ $\mathrm{V}_{6} \mathrm{O}_{24}$ and $\mathrm{EuVO}_{4}$ with micro-homogeneity. The phosphor show both a broad emission with an maximum at $520 \mathrm{~nm}$ coordinating to $\mathrm{CT}$ of $\left[\mathrm{VO}_{4}\right]^{3-}$ and a sharp emission around $617 \mathrm{~nm}$ ascribing to electric dipole transition $\left({ }^{5} \mathrm{D}_{0} \rightarrow{ }^{7} \mathrm{~F}_{2}\right)$ of $\mathrm{Eu}^{3+}$, and it can be proved that the efficient energy transfer from $\left[\mathrm{VO}_{4}\right]^{3-}$ to $\mathrm{Eu}^{3+}$ exists. The emission color of the product can be tuned from yellow-green to red via white by both adjusting the Eu concentration and the temperature. The intensities of sharp emission at $617 \mathrm{~nm}$ first increase and then decrease with $\mathrm{Eu}^{3+}$ concentration, and the maximum is reached at the value of $20 \mathrm{~mol} \%$. The white light emission is also realized at the value of $15 \mathrm{~mol} \%$. The ratio between the intensities $(R)$ of broad emission around $520 \mathrm{~nm}$ and that of the sharp peak at $617 \mathrm{~nm}$ changes linearly as the temperature rising from $295 \mathrm{~K}$ to $480 \mathrm{~K}$. The relative sensitivity reaches the maximal value at $455 \mathrm{~K}$ and the maximal value equals to $1.83 \%$, which promises a potential application of $\mathrm{CMV}: \mathrm{Eu}^{3+}$ phosphor as a luminescent temperature sensor.

\section{Conflicts of interest}

There are no conflicts to declare.

\section{Acknowledgements}

This work was supported by the projects from the National Natural Science Foundation of China (grant no. 51632003, 51302106, 51501071 and 51802114).

\section{References}

1 K. Z. Zheng, Z. Y. Liu, C. J. Lv and W. P. Qin, J. Mater. Chem. C, 2013, 1, 5502-5507.

2 F. C. Hawthorne, J. Solid State Chem., 1977, 22, 157-170.

3 G. M. Thomas and M. J. Damzen, Opt. Express, 2011, 19, 4577-4582.

4 J. Azkargorta, M. Bettinelli, I. Iparraguirre, S. Garcia-Revilla, R. Balda and J. Fernández, Opt. Express, 2011, 19, 1959119599.

5 Y. J. Huang, Y. P. Huang, H. C. Liang, K. W. Su, Y. F. Chen and K. F. Huang, Opt. Express, 2010, 18, 9518-9524.

6 M. Koichi, K. Miyamoto, S. Ujita, T. Saito, H. Ito and T. Omatsu, Opt. Express, 2011, 19, 18523-18528.

7 Y. L. Huang, Y. M. Yu, T. Tsuboi and H. J. Seo, Opt. Express, 2012, 20, 4360-4368.

8 D. Haranath, H. Chander, P. Sharma and S. Singh, Appl. Phys. Lett., 2006, 89, 173118.

9 X. Y. Liu, N. Ding, C. N. Qu, Y. S. Zhu and T. Ye, Chin. J. Lumin., 2017, 38, 587-593.

10 E. I. Voit, A. V. Voit, A. V. Gerasimenko and V. I. Sergienko, J. Struct. Chem., 2000, 41, 206-211.

11 I. A. Bondar and N. A. Toropov, Mater. Res. Bull., 1967, 2, 479-489. 
12 A. A. Kaukis, J. E. Tiliks, V. V. Tamuzhs, A. A. Abramenkovs and V. G. Vasiljev, Fusion Eng. Des., 1991, 17, 13-16.

13 P. R. K. Kunchala, S. N. Achary, A. K. Tyagi and B. S. Naidu, Cryst. Growth Des., 2019, 19, 3379-3388.

14 X. Liu, Z. Xu, C. Chen, D. Tian, L. Yang and X. Luo, J. Mater. Chem. C, 2019, 7, 2361-2375.

15 S. E. Kichanov, Y. E. Gorshkova, G. E. Rachkovskaya, D. P. Kozlenko, G. B. Zakharevich and B. N. Savenko, Mater. Chem. Phys., 2019, 237, 121830.

16 J. Pejchal, J. Barta, T. Trojek, R. Kucerkova, A. Beitlerova and M. Nikl, Radiat. Meas., 2019, 121, 26-31.

17 C. J. Liu, Z. F. Zhou and Y. Zhang, J. Lumin., 2019, 213, 1-5. 18 S. M. Rafiaei, T. D. Isfahani, H. Afshari and M. Shokouhimehr, Mater. Chem. Phys., 2018, 203, 274-279.

19 Y. S. Chang, F. M. Huang and Y. Y. Tsai, J. Lumin., 2009, 129, 1181-1185.

20 X. Min, Z. Huang and M. Fang, J. Nanosci. Nanotechnol., 2016, 16, 3684-3689.

21 J. Y. Park, J. W. Chung and H. K. Yang, Optik, 2018, 155, 384389.

22 J. Huang, Q. Li and D. Chen, Mater. Sci. Eng., B, 2010, 172, 108-113.

23 W. Xu, X. Y. Gao, L. J. Zheng, Z. G. Zhang and W. W. Cao, Opt. Express, 2012, 20, 18127-18137.

24 V. K. Rai, D. K. Rai and S. B. Rai, Sens. Actuators, A, 2006, 128, 14-17.

25 P. V. dos Santos, M. T. de Araujo, A. S. Gouveia-Neto, J. A. Medeiros Neto and A. S. B. Sombra, Appl. Phys. Lett., 1998, 73, 57-580.

26 D. G. Lee, C. R. Kesavulu, S. S. Yi, S. Cho, K. Jang, S. H. Kim and J. H. Jeong, J. Nanosci. Nanotechnol., 2014, 14, 58775880 .

27 X. Min, M. H. Fang, Z. H. Huang, Y. G. Liu, C. Tang and X. W. Wu, Inorg. Chem., 2014, 53, 6060.

28 D. A. Hakeem and K. Park, J. Nanosci. Nanotechnol., 2015, 15, 5074.

29 L. K. Bharat, S. K. Jeon, K. G. Krishna and J. S. Yu, Sci. Rep., 2017, 9, 42348.

30 W. Xu, C. R. Li, B. S. Cao and B. Dong, Chin. Phys. B, 2010, 12, 127804.
31 X. Yang, Z. Fu and Y. Yang, J. Am. Chem. Soc., 2015, 98, 25952600.

32 Y. M. Yang, Ceram. Int., 2014, 40, 9875-9880.

33 M. Quintanilla, E. Cantelar, F. Cusso and M. Villegas, Appl. Phys. Express, 2011, 4, 022601.

34 L. Li, C. F. Guo, S. Jiang, D. K. Agrawal and T. Li, RSC Adv., 2014, 4, 6391.

35 P. V. dos Santos, M. T. de Araujo and J. A. Gouveia-Neto, Appl. Phys. Lett., 1998, 73, 578-580.

36 B. Dong, D. P. Liu, X. J. Wang, T. Yang, S. M. Miao and C. R. Li, Appl. Phys. Lett., 2007, 90, 4743.

37 G. Bayer, J. Am. Ceram. Soc., 1965, 48, 600.

38 H. Müller-Buschbaum and M. von Postel, Z. Anorg. Allg. Chem., 1992, 615, 101-103.

39 T. Nakajima, M. Isobe and T. Tsuchiya, J. Phys. Chem. C, 2010, 114, 5160-5167.

40 X. Min, Z. Huang, M. Fang, Y. G. Liu, C. Tang and X. Wu, J. Nanosci. Nanotechnol., 2016, 16, 3684-3689.

41 J. Y. Park, J. W. Chung and H. K. Yang, Optik, 2018, 155, 384389.

42 Y. C. Kang and S. B. Park, Res. Bull., 1999, 14, 2611-2615.

43 Y. Pu, Y. Huang, T. Tsuboi, W. Huang, C. Chen and H. J. Seo, Mater. Lett., 2015, 149, 89-91.

44 S. Zhou, C. K. Duan and S. Han, Dalton Trans., 2018, 47, 1599-1603.

45 G. Blasse and B. C. Geiabmaier, A vanadate-based white light emitting luminescent material for temperature sensing, Springer Berlin, 1994.

46 G. S. Ofelt, J. Chem. Phys., 1962, 37, 511.

47 B. R. Judd, Phys. Rev., 1962, 127, 750.

48 A. F. Pereira, K. U. Kumar and W. F. Silva, Sens. Actuators, B, 2015, 213, 65-71.

49 X. Tian, X. Wei and Y. Chen, Opt. Express, 2014, 22, 3033330345.

50 R. Shi, L. T. Lin and P. Dorenbos, J. Mater. Chem. C, 2017, 5, 10737-10745.

51 J. Eldridge, J. Lumin., 2019, 214, 116535.

52 S. D. Li, Q. Y. Meng, S. C. Lü and W. J. Sun, Spectrochim. Acta, Part A, 2019, 214, 537-543. 